\title{
Modeling and Simulation of ABS Hydraulic Control Unit CAI Jian-wei ${ }^{a}$, CHU Liang ${ }^{b}$, CHENG Wei-feng $^{c}$, WANG Yan-bo $^{d}$ \\ Jilin University, Changchun, Jilin Province 130022, P.R. China \\ ajianweicai@163.com, bchuliang@jlu.edu.cn, cc5085185@gmail.com, dwyb-08@163.com
}

Keywords: Simulation; ABS; Hydraulic Unit; Increase Pressure; Decrease Pressure.

\begin{abstract}
In-depth analysis of the composition and working principle of the anti-lock braking (ABS) system hydraulic control unit (HCU),establish the mathematical model of the major components of the solenoid valves, motors and pump, establish the model of the HCU in the MATLAB / Simulink environment . By simulation the experiment of the pressure increase and decease on the HCU, results show that the accuracy and precision of the model. Provide an efficient and convenient platform for the rapid development of integrated control of the vehicle ABS hydraulic unit.
\end{abstract}

\section{Introduction}

Vehicle anti-lock braking system (ABS) is an important active safety systems, ABS performance related to the security issues of human life, the performance of the key components of the ABS system HCU significantly affect the performance of the ABS[1]. As an important executive body of the ABS, HCU received the instructions of the electronic control unit, should be able to timely adjust the wheel brake cylinder pressure, so its performance will directly affect the control effect of the wheel cylinder pressure of the hydraulic control system. HCU's performance characteristics depend on the relationship between the HCU physical structural characteristics and features of physical structure and control signals[1], and therefore must be in-depth analysis of the composition and working principle of the HCU, the establishment of the correct, high-precision physical model to simulate and analyze, guide design and production of HCU.

\section{Model Establishment}

The ABS system is generally composed of three parts by the controller (ECU), hydraulic modulator (HCU) and wheel speed sensors. Currently, the vast majority of ABS solenoid valve structure of the hydraulic control unit. Figure 1 shows a typical structure of the ABS hydraulic system composed of front and rear axle with disc brakes. In braking, the brake pedal force after amplification of the vacuum booster, the role of the master cylinder on; master cylinder two output pipe using $X$ program layout, respectively, pressure on the two wheels cross through increased pressure valves and pressure reducing valve to adjust the pressure changes. Conventional brake booster valve open, pressure reducing valve is normally closed, brake fluid into the wheel cylinder, hydraulic building; in emergency braking, the driver depresses the brake pedal, the pressure rises quickly when the wheels sudden death trends, the booster valve closed, for packing, if the wheels are still violent death trends in pressure relief valve to open decompression, so that the wheel speed to full recovery, and then returned to normal booster, and so forth, making the wheel slip ratio to maintain near the optimum slip ratio[2]. 


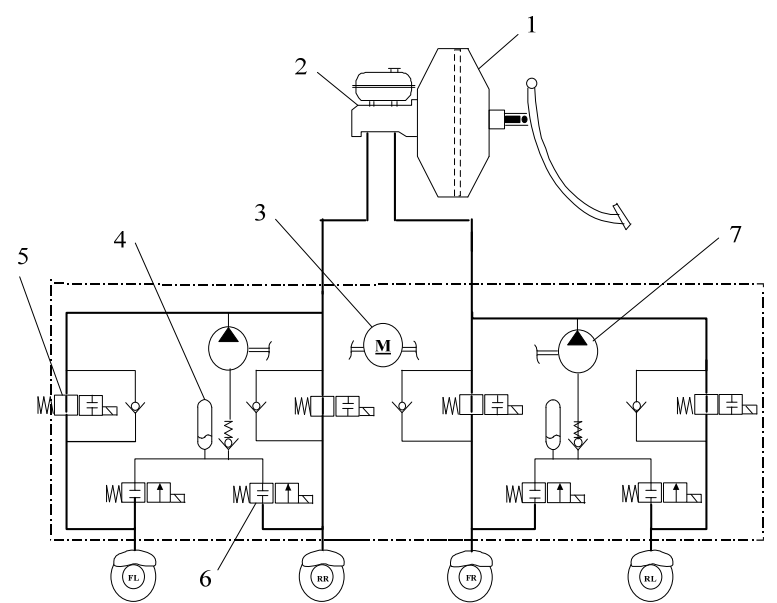

Fig 1 One wheel hydraulic circuit model

Where: 1- Vacuum booster;2-Master cylinder;3-motor;4-accumulator;5-Inlet valve;6-Outlet valves;7-pump

Model of Valve. Hydraulic brake ABS inlet valve is generally used high speed switch electromagnetic valve. It is consisted by every magnetic tube, the action of iron, valve, push rod, valve seats, filters, filter holder and so on[3].

$$
\begin{aligned}
& \frac{d i}{d t}=\frac{1}{L(x, i)+i \cdot \frac{\partial L(x, i)}{\partial i}}\left[U-R \cdot i-\frac{\partial L(x, i)}{\partial i} \cdot i \cdot v\right] \\
& \frac{d v}{d t}=\frac{1}{m}\left[F_{m}(x, i)-k \cdot\left(x+G_{0}\right)-F_{p}(x)-b \cdot v^{3}-F_{f}\right] \\
& \frac{d x}{d t}=v
\end{aligned}
$$

Where: $U$-Solenoid valve drive voltage; $i$-current in the valve; $R$-valve coil resistance; $L$-Valve coil inductance; $x, v$--Displacement and speed of the spool shifts; $m$--Spool quality; $F_{m}, F_{f}$--Electromagnetic force and friction; $k$-Return spring stiffness; $F_{p}$-Spool components suffered fluid power; $b$-Speed damping; $G_{0}$-Spring preload.

Model of Pump. The input of the return flow Pump is the drive moment from the motor [4].

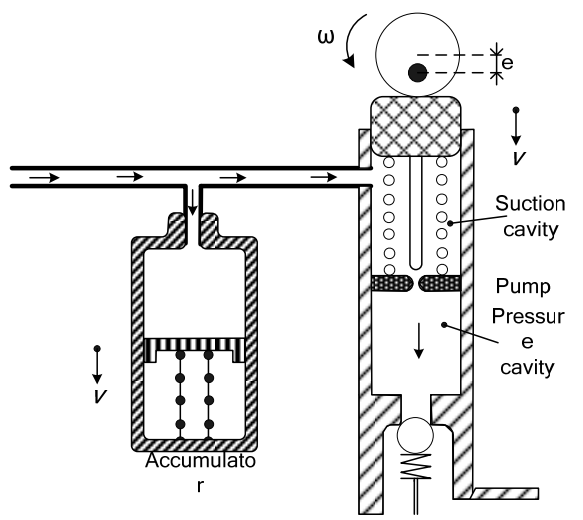

Fig 2 Construction of accumulator and pump

Volume of pressure cavity is calculated as:

$$
V=A \cdot e \cdot \sin \left(\varphi_{0}+\omega \cdot t\right)
$$

Where: $A$-area of pump piston; $e$-eccentricity; $\varphi_{0}$-the initial angle of eccentric wheel; $\omega$-motor angular speed; $t$-time.

And the flow quantity is calculated as:

$$
q=\dot{V}=A \cdot e \cdot \cos \left(\varphi_{0}+\omega \cdot t\right) \cdot \omega
$$


And equivalent pressure of the pump piston is calculated as:

$$
p=p_{\text {out }}-f \cdot p_{\text {in }}
$$

Where: $p_{\text {out }}$--the pressure in the pressure cavity; $p_{\text {in }}$ - the pressure in the suction cavity; $f$-ratio of area between pressure cavity and suction cavity.

And the resistance moment that pump feeds back to motor is calculated as:

$$
M=q \cdot p
$$

Model of Motor. The model of permanent magnet DC motor is description as:

$$
\begin{aligned}
& \frac{d i}{d t}=\left(U-i \cdot R-k_{-} \varphi \cdot \omega\right) / L \\
& \dot{\omega}=\left[k_{-} \varphi \cdot i-\left(M+m_{0}\right)\right] / J
\end{aligned}
$$

Where: $U$-switch voltage; $i$-current in the motor coil; $R$-motor coil resistance; $\omega$-motor angular speed; $k_{-} \phi$-electromagnetic coefficient; $L$-motor coil inductance; $M$-resistance moment from pump; $m_{0}$-motor friction moment; $J$-moment of inertia.

Model of Accumulator. Relationship between the cavity length and volume of accumulator is as below [5]:

$$
\begin{aligned}
& l_{e}=x_{0} \cdot x_{1} \\
& V=l_{e} \cdot \pi \cdot d^{2} / 4
\end{aligned}
$$

Where: $l_{\varepsilon}$-- the cavity length of accumulator; $x_{0}$-- the initial length of accumulator cavity; $x_{1}$-displacement of piston; $d$-diameter of piston.

The flow quantity of braking liquid into the accumulator is calculated as below:

$$
q=v \cdot \frac{\pi}{4} \cdot d^{2} \cdot \frac{\rho(P)}{\rho(0)}
$$

Where: $v$-piston moving speed; $\rho(P)$-liquid density at pressure $P ; P$-Pressure in the accumulator.

And the dynamic equation of the piston is as below:

$$
\begin{aligned}
& F=l_{e} \cdot k-\frac{\pi}{4} \cdot d^{2} \cdot P \\
& F=m \cdot \dot{v}=m \cdot \ddot{x}_{1}
\end{aligned}
$$

Where: $k$-spring stiffness; $m$-piston mass.

\section{Simulation}

Model Parameter Setting. Before simulation, parameters of accumulator, pump and motor should be initially identified. In model, resistance of the motor is $0.125 \mathrm{ohm}$, coil inductance is $9.34 \mathrm{e}-5 \mathrm{H}$, moment of inertia is $9.5 \mathrm{e}-5 \mathrm{~kg} * \mathrm{~m} 2$, and frictional torque is $0.3 \mathrm{~N} * \mathrm{~m}$. the volume of accumulator is $5.3 \mathrm{ml}$, and its spring stiffness is $6200 \mathrm{~N} / \mathrm{m}$, and diameter of piston is $24 \mathrm{~mm}$. Eccentricity of pump is $1 \mathrm{~mm}$, and diameter of pump piston is $1 \mathrm{~mm}$.

\section{Results}

In order to verify the correctness of the model, the increase pressure and decrease pressure experiments is implemented with the HCU, the HCU receives the control signal which gets from the target pressure of the experiments. 


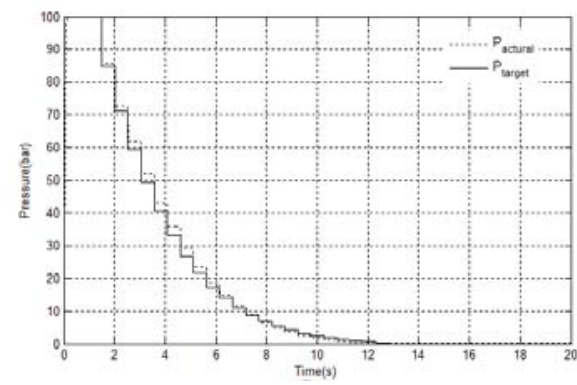

Fig 3 Increase pressure( $\mathrm{D}=1.16 \mathrm{~mm})$

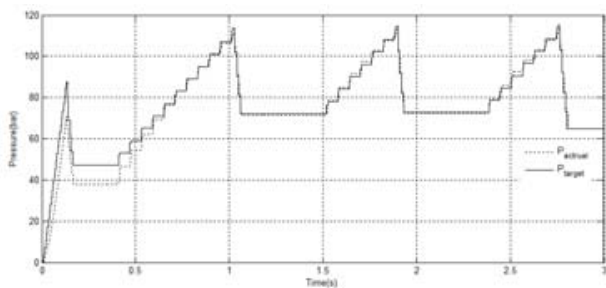

Fig 5 Decrease pressure $(\mathrm{L}=0.23 \mathrm{~mm})$

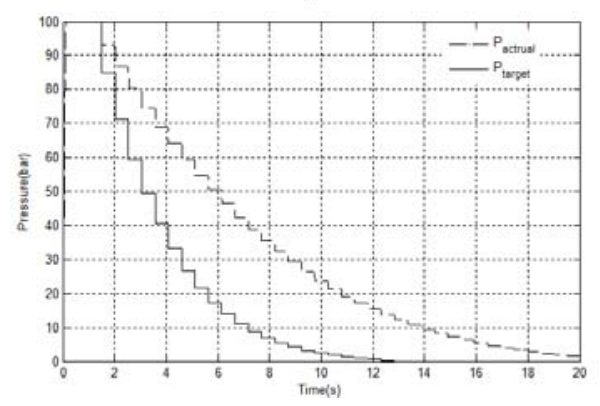

Fig 4 Increase pressure( $\mathrm{D}=0.74 \mathrm{~mm})$

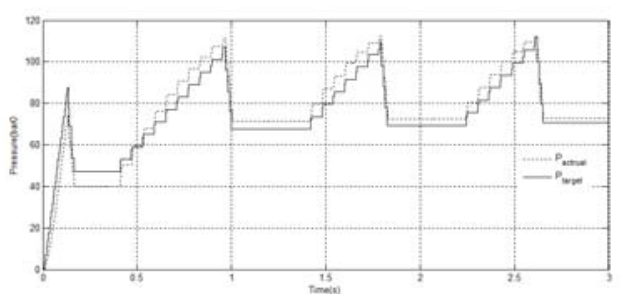

Fig 6 Decrease pressure $(\mathrm{L}=0.33 \mathrm{~mm})$

From these figures above, the diameter of the outlet valves is $1.16 \mathrm{~mm}$ in figure3.the actual pressure can follow the target pressure better. While the diameter of the outlet valves is $0.74 \mathrm{~mm}$ in figure4. The result is bad. As the figure 5 and figure6 shown, it change the maximum displacement of the tappet of the inlet valves, the value is $0.23 \mathrm{~mm}$ and $0.33 \mathrm{~mm}$, the result is better in figure 5 where the value is $0.23 \mathrm{~mm}$.

\section{Acknowledge}

Project 20121092 supported by Graduate Innovation Fund of Jilin University, and Project 2010DFB70360 of Program of International S\&T Cooperation.

\section{Reference}

[1]Chu Liang, Ou Yang, et al. Automobile Technology, 2010(9): 20 23.

[2]Yu Liangyao,Wang Huiyi, et al. Chinese Journal of Mechanical Engineering, 2007, 43(9):40 46.

[3] J.H. XIE. Automotive ESP Hydraulic Modulator Modeling and Control Logic Analysis[D], Jilin University, Changchun, China. 2008:18-19

[4] D.W. GAO. Research on Hydraulic Modulator Modeling and Brake Pressure Estimation for Vehicle Electronic Stability Program [D], Jilin University, Changchun, China. 2009:11-29

[5] R. TAO, H. ZHANG, D.C. FU, et al. Transactions of the CSAE, 2010, 26(3): 135-139. (in Chinese with English abstract) 